\title{
Student perspectives of online learning during the covid-19 pandemic
}

\author{
Adnan Chawdhry, California University of PA, chawdhry_A@calu.edu \\ Karen Paullet, Robert Morris University, paullet@rmu.edu \\ Jeanne Baugh, Robert Morris University,baugh@rmu.edu \\ Debra Nakama, University of Hawaii Maui, College, debran@hawaii.edu
}

\begin{abstract}
In 2020, the world was turned upside down due to the COVID-19 virus requiring organizations to quickly adopt new working models that provided safe accommodations for stakeholders. Higher education was not exempt from this disruption and required a rapid response to move to remote / online learning during the COVID-19 pandemic. While universities acted quickly in response to this virus, this swift change had a direct impact on the faculty, students, and stakeholders of the universities. This study analyzed students' perceptions on how learning was impacted during this transition from in-person classes to remote classes and if they were adequately prepared to be successful. The study provides a quantitative assessment of the impact of student learning during the COVID-19 pandemic at two small rural Mid-Atlantic universities. A survey was distributed with 139 respondents at the undergraduate and graduate level to understand how the pandemic has impacted their courses in the $2020-2021$ academic year and what preparation they have received during this emergency transition. The results of the study were analyzed to understand students' level of learning in the "new environment" with their final grades and correlates it to their access to technology, tools used in the classroom, and training they had received. The outcome of this study is to find areas where higher education institutions can improve their process in emergency situations requiring student to transition to a completely remote environment.
\end{abstract}

Keywords: online learning, hybrid, Covid 19, pandemic, distance learning, remote learning

\section{Introduction}

The COVID-19 pandemic has caused a major disruption to all phases of society, and higher education has not been spared. Distance measures required to prevent the spread of the disease have led to institutions implementing virtual education. The COVID-19 pandemic has disrupted higher education to a level of emergency. Students were forced from their seats in a classroom to learning at a distance. With very little notice faculty were required to move their classes to a virtual environment. In some instances, little to no training was involved. Students were also required to move to online learning. Many students were learning for the first time in a virtual setting. It is important to note that some students did not have access to computers, technology such as webcams and microphones or the Internet from home often leading to a distressed learning environment. Emergency remote learning (ERL) was implemented worldwide during the pandemic.

Online learning is different than emergency remote learning. The intent of emergency remote learning is to provide temporary access to teaching and teaching aids in a timely manner and to not recreate the educational system. The push to an immediate remote learning environment created an initial panic on both 


\section{Issues in Information Systems}

Volume 22, Issue 4, pp. 221-230, 2021

students and faculty. As of July 2020, $98.6 \%$ of learners worldwide were affected by the pandemic totaling 1.725 billion students from pre-primary to higher education institutions in 200 counties (United Nations, 2020). This exploratory study of 139 students will assess the student's perspectives of learning remotely during the COVID-19 pandemic. The following research questions were studied:

RQ1: How has COVID-19 impacted student learning throughout the 2020-1021 academic year?

RQ2: Were students adequately prepared for the sudden push to remote learning during the 2020-2021 academic year?

\section{Literature Review}

Worldwide lockdowns have interrupted education causing school closures that have lasted more than a year at the time of this study in 2021. In a moment's notice students were forced to rely on their own resources to continue learning remotely. In addition, faculty had to adapt to new pedagogical concepts and modes of delivery often with little to no training (Schleicher, 2020). Higher education institutions had to deal with border closings which specifically affected their international students. This alone could affect student's legal status in their host country. To ensure the continuous flow of education institutions moved to online classes. Although universities offered online classes prior to the pandemic, most traditional students did not consider online learning as their first choice. The pandemic has shown that students do not want to spend a vast amount of money for online classes and content. In addition to education students attend universities to meet people, play sports, collaborate and to live on campus (Schleicher, 2020).

The flexibility of E-Learning compared to face-to-face teaching has led to many students becoming "selfdirected learners" (Keis, 2017). However, some studies have shown that several learners have difficulty with self-discipline. There must be an ongoing interaction between students and instructors, along with a stated clarity of the requirements and goals of the learning process (Docherty and Sandhu, 2006). Research has shown that two-way feedback helps the student to stay connected and motivated (Keis, 2017). This interaction, along with social support is essential in the success of this type of modality (Bernard et al. 2009). Social and collaborative learning allows students to work together and expand their knowledge in a collective forum.

Literature reveals that the pandemic has disrupted higher education to a level of emergency. The following are issues that have been identified (Elfirdoussi et al, 2020):

- The economic dimension: the infrastructures, platforms, hardware, software, tools, Internet, connection debit, etc.

- The psychological dimensions: the change from traditional education to e-learning.

- The social dimension: the use of technology, its management, its regulation, trust, and security which will change our national and international behaviors as individuals, institutions, and government.

○ The environmental dimensions: from home to home, defining what field, medicines, feedback, etc.

Online learning is an interdisciplinary field that has evolved over time and has served well to meeting learning needs and guide open educational practices. Information and communication technology (ICT) when applied successfully in instruction, learning, and assessment, is considered a powerful tool for educational change and reform in distance learning. However, the literature also reveals the use of suitable 


\section{Issues in Information Systems}

Volume 22, Issue 4, pp. 221-230, 2021

and relevant pedagogy for online learning depends on the expertise and exposure of both faculty and students to ICT.

It is important to note that there are substantial differences between online learning and emergency remote learning (ERL). Online learning is typically developed with lessons, lectures and a design plan which often must be approved internally at academic institutions prior to deployment. Whereas, ERL is a hurried shift in instructional delivery due to a crisis (Ho et al, 2021). This force to an immediate action for online delivery has led to issues with lessons, technology, and planned pedagogical methods. The objective is to provide quick and, in most instances, temporary teaching support.

A study conducted by Ho, et.al (2021) examined undergraduate higher education students' satisfaction during emergency remote learning. The researchers distributed a survey to 3219 registered students of their university in which 425 students participated. The study examined 6 factors to include readiness, accessibility, instructor related, assessment-related, learning-related and self-concern in regard to EML during the COVID-19 pandemic. Students were asked to self-rate their digital knowledge using a scale of 1 to 10 . The average result was 6.36 out of 10 which if this were an assignment would be a D grade. Additional results showed that 5.12 out of 7 or $73 \%$ of students prefer face-to-face learning.

Internet connection problems and poor digital skills on the student's part led to hurtles for attaining success in an online course (Niebuhr, et al., 2014). Faculty and students as well, should be thoroughly trained in the particular E-learning system being implemented. The IT department should provide support and direction before and during an online course (Baczek et al., 2021). Faculty should be trained in various types of distance learning techniques they may want to implement in their online classroom. One study even recommended that the faculty member be given "a reduction in cognitive load and increased interactivities during online teaching" (Mukhtar et al., 2020).

Various E-learning tools have been shown to be effective supporting virtual education (Soltanimehr et al., 2019 and Varthis and Anderson, 2016). Students have demonstrated that the knowledge gained through these methods is equivalent to that gained through face-to-face learning. Previous studies have also shown that student's satisfaction, motivation, engagement, and performance is increased through blended learning (Donkin, Askew, Stevenson, 2019). But, the student's perception of online education may be highly related to the area of study. For example, in a study of medical students participating in distance education during the pandemic, it was reported that the material presented was done so in a very organized and effective manner. But the students also felt that they were missing the clinical and social skills necessary in their field (Baczek et al., 2021).

Universities and institutions world-wide had to turn to e-learning tools during the change from face-to-face to remote learning. This has shown to be a disadvantage for some institutions because they did not have the proper infrastructure in place to facilitate learning at the start of the pandemic. As mentioned by Pokhrel, et. Al. (2021), there is not a one size fits all approach to online learning (Pokhrel,,Chhetri, 2021). Different subjects, let alone different age groups require a multitude of approaches to online learning making it difficult to have a one size fits all model. In addition, students living and learning at home have shown both psychological and emotional distress and are often unable to engage in the online environment.

Challenges with e-learning are accessibility, affordability, flexibility, learning pedagogy, life-long learning, and educational policies (Murgatrotd, 2020). There are potential issues with reliable Internet, families that cannot afford computers, microphones, cameras and a student's lack of exposure to learning remotely. Students that are motivated learners were unaffected by the push to remote learning as compared to students who have difficultly learning in person and that need direct supervision. Students also learn social and 


\section{Issues in Information Systems}

Volume 22, Issue 4, pp. 221-230, 2021

communications skills which in part is missing in the quick push to remote learning. Students were ripped from their normal schedules of schools. The social and psychological implications must be recognized.

\section{Methodology}

This study examined students at two small mid-Atlantic Universities during the period of March to May 2021. The research utilized a quantitative methodology to assess student's perspectives of moving to online learning during the emergency COVID-19 pandemic. The population chosen for this study was comprised of students aged 18 and older at both universities. A total of 139 respondents completed the survey. The survey was conducted using Survey Monkey, an online tool, to gather and organize data. The data was imported into SPSS for further analysis. The researchers used Chi-square with a statistical significance at the .05 margin of error with a $95 \%$ confidence level. The study was a convenience sample surveying students enrolled in courses from the School of Arts and Humanities, Business, Science and Math, Engineering, Computer Science, Computer Information Systems, Criminal Justice and Psychology. The study explores the following two research questions:

RQ1: How has COVID-19 impacted student learning throughout the 2020-1021 academic year?

RQ2: Were students adequately prepared for the sudden push to remote learning during the 2020-2021 academic year?

The survey instrument consisted of 20 close ended questions and one open ended question for further understanding of participant experiences in moving to remote learning during the COVID-19 pandemic. The first three questions focused on background information for the students including their gender, level of education, and school / department affiliation. The next set of questions focused on the students' course delivery method during the pandemic, the LMS / tools being used for the course, and the trainings provided by the university to the students and faculty. Additionally, the participants answered questions on their performance in the course, availability / usage of technology, and overall impact to their learning and final grades. Finally, the students were given an opportunity to respond in an open question on how the COVID19 pandemic has impacted their grades.

\section{Results}

Students were asked background questions around their gender and level of education. Of the 139 Students, $60.4 \%$ were male, $37.4 \%$ were female, and $2.2 \%$ preferred not to provide this information at the time of the survey. The researchers also found it important to understand the students' level of education as it may correlate with their overall impact during the pandemic. Of the participants, $19.4 \%$ were freshman, $15.1 \%$ were sophomores, $24.5 \%$ were juniors, $29.5 \%$ were seniors, $7.9 \%$ were doing graduate work, and $3.6 \%$ were post-graduate students. The breakdown of student's level of learning can be seen in Table 1 below.

Table 1: Level of Education

\begin{tabular}{|l|c|}
\hline \multicolumn{2}{|l|}{} \\
\hline Freshman & $19.4 \%$ \\
\hline Sophomore & $15.1 \%$ \\
\hline Junior & $24.5 \%$ \\
\hline Senior & $29.5 \%$ \\
\hline Masters (Graduate) & $7.9 \%$ \\
\hline Doctorate (Post-Graduate & $3.6 \%$ \\
\hline
\end{tabular}




\section{Issues in Information Systems}

Volume 22, Issue 4, pp. 221-230, 2021

Prior to the emergency transition of learning, students were asked how their education was primarily being conducted during the Spring 2020 semester. This question allowed students to select more than one response with the results of $43.9 \%$ of students had online classes, $46 \%$ of students had face-to-face sessions, and $25.2 \%$ were in a hybrid model. Of the participants, $90.4 \%$ responded that they were required to move to a fully remote / online format of classes during the pandemic while $21.6 \%$ remain unaffected.

Students were asked which primary tool was used to for their fully remote / online course during the pandemic. Of the respondents, $62.5 \%$ responded with video conferencing tools, $32.4 \%$ used discussion boards, $2.9 \%$ used Collaboration tools like SharePoint and Microsoft Teams, and 2.2\% leveraged phone calls. As a pre-requisite for these tools, $33.8 \%$ of the students reported that the university provided them training on the tools while $66.2 \%$ did not receive training. Finally, $54 \%$ of the students reported that their instructor seemed adequately trained and prepared to teach in the fully remote / online format.

With technology being on the forefront of student needs during this transition, it was important to understand what was available and used during the courses. Based on the student responses, $92.8 \%$ of the students had reported they had access to adequate technology to complete their course while $7.2 \%$ felt they did not. Students were then asked which technologies were needed to complete their course work and the respondents were permitted to chose more than one. The results can be seen in Table 2 below. In only $29.5 \%$ of the student cases, the university provided the technology needed to complete the course while $70.5 \%$ did not receive these technologies from the university. Of the students who reported they did not receive the technology from the university, $47.4 \%$ stated they had to purchase technology to continue their education during the pandemic while $52.6 \%$ stated they did not require purchasing new technology. Lastly, students were asked if purchasing or acquiring the technology caused them an undue burden and $76.3 \%$ of the students responded yes while $23.7 \%$ responded no.

Table 2: Course Technology

\begin{tabular}{|c|c|}
\hline Computer & $97.1 \%$ \\
\hline Webcam & $82.0 \%$ \\
\hline Microphone & $84.2 \%$ \\
\hline Printer & $31 . \%$ \\
\hline Internet & $95.0 \%$ \\
\hline
\end{tabular}

A subsequent series of questions aimed to understand student's educational impacts due to the COVID-19 transition in the Spring 2020 semester. Of the participants, 54\% stated that the change in instructional delivery did impact their grade while $46 \%$ did not feel the impact. Students were asked two questions on their level of learning in the fully remote environment versus attending their face-to-face classes. Over $50 \%$ reported some decline in learning compared to face-to-face classes. The results can be seen in table 3 below. Additionally, students were asked of the impact to their final grades due to the Pandemic and 28.8\% of students reported some negative impact to their final grade. These results can be seen in Table 4 below.

Table 3: Impact to Learning

\begin{tabular}{|l|c|}
\hline \multicolumn{2}{|c|}{} \\
\hline Extremely Improved & $3.6 \%$ \\
\hline Improved & $7.9 \%$ \\
\hline No Change & $25.2 \%$ \\
\hline Declined & $50.4 \%$ \\
\hline Extremely Declined & $12.9 \%$ \\
\hline
\end{tabular}


Table 4: Final Grade Impact

\begin{tabular}{|l|c|}
\hline Extremely Improved & $2.2 \%$ \\
\hline Improved & $18.7 \%$ \\
\hline No Change & $50.4 \%$ \\
\hline Declined & $26.6 \%$ \\
\hline Extremely Declined & $2.2 \%$ \\
\hline
\end{tabular}

The researchers wanted to correlate the students perceived level of learning with training that was provided to themselves and their perceptions of instructors being adequately trained. Only $33 \%$ of the students felt they had been provided training by the university. Listed in Table 5, the largest number of respondents stated that they did not receive training and their level of learning did indeed decline. The lowest response was students who saw an extremely improved level of learning and did not receive training. Further analysis of these two variables using chi-square resulted in a significance value of .205 with a chi-square value of 5.928 which unfortunately does not show a statistical significance between these two variables. However, a similar analysis was done comparing the level of learning and the perception of instructors being trained for their course. The results can be seen below in Table 6 with the largest response around a declined level of learning and perceiving that the instructors were not adequately trained. Another chi-square analysis was run on the variables of level of learning and perception of instructors being adequately trained resulting in a significance value of 0 and a chi-square value of .001 illustrating there was a statistical significance between these variables.

Table 5: Level of Learning Vs. Training Provided

\begin{tabular}{|l|c|c|}
\hline & \multicolumn{2}{|c|}{} \\
\hline Extremely Improved & $1.4 \%$ & $2.2 \%$ \\
\hline Improved & $3.6 \%$ & $4.3 \%$ \\
\hline No Change & $15.1 \%$ & $10.1 \%$ \\
\hline Declined & $36.6 \%$ & $13.7 \%$ \\
\hline Extremely Declined & $9.4 \%$ & $3.6 \%$ \\
\hline
\end{tabular}

Table 6: Level of Learning Vs. Instructors Trained

\begin{tabular}{|l|c|c|}
\hline & & \\
\hline Extremely Improved & $0.7 \%$ & $2.9 \%$ \\
\hline Improved & $0.7 \%$ & $7.20 \%$ \\
\hline No Change & $7.20 \%$ & $18.0 \%$ \\
\hline Declined & $28.10 \%$ & $22.30 \%$ \\
\hline Extremely Declined & $9.4 \%$ & $3.6 \%$ \\
\hline
\end{tabular}

Level of learning was compared with three additional variables around the students' performance in the courses, the impact to their instructional delivery, and their final grade impact. The highest resulting response was that students saw their performance get worse and their level of learning declined. Approximately one-third of the students reported decreased performance with some level of a decline in learning. The full results can be found in Table 7 below. Table 8 illustrates the cross between the level of learning and if the students found an impact in the instructional delivery. Approximately $44.6 \%$ of the students found some level of decline in their learning and an impact with their instructional delivery. The final correlation was to understand the link between the level of learning and the students' final grade in the course. Table 9 below illustrates the cross between these two variables and shows that the highest 


\section{Issues in Information Systems}

Volume 22, Issue 4, pp. 221-230, 2021

values represent a decline in learning and either a decline or no change in the final grade. Each of these three variables were analyzed with chi-square and the resulting values can be found in Table 10 below. All three variables had a statistical significance with the students' level of learning.

Table 7: Level of Learning Vs. Worse Performance

\begin{tabular}{|c|c|c|c|}
\hline Extremely Improved & $3.6 \%$ & $0 \%$ & $0 \%$ \\
\hline Improved & $6.5 \%$ & $1.4 \%$ & $0 \%$ \\
\hline No Change & $9.4 \%$ & $15.1 \%$ & $0.7 \%$ \\
\hline Declined & $9.40 \%$ & $18 \%$ & $23.0 \%$ \\
\hline Extremely Declined & $2.9 \%$ & $1.4 \%$ & $8.6 \%$ \\
\hline
\end{tabular}

Table 8: Level of Learning Vs. Delivery Impact

\begin{tabular}{|l|c|c|}
\hline Extremely Improved & $2.2 \%$ & $1.4 \%$ \\
\hline Improved & $5.8 \%$ & $2.2 \%$ \\
\hline No Change & $19.3 \%$ & $5.8 \%$ \\
\hline Declined & $16.5 \%$ & $33.8 \%$ \\
\hline Extremely Declined & $2.2 \%$ & $10.8 \%$ \\
\hline
\end{tabular}

Table 9: Level of Learning Vs Final Grade Impact

\begin{tabular}{|c|c|c|c|c|c|}
\hline Extremely Improved & $0.7 \%$ & $2.9 \%$ & $0.0 \%$ & $0.0 \%$ & $0.0 \%$ \\
\hline Improved & $0.7 \%$ & $4.3 \%$ & $2.2 \%$ & $0.7 \%$ & $0.0 \%$ \\
\hline No Change & $0.0 \%$ & $5.8 \%$ & $17.30 \%$ & $2.2 \%$ & $0.0 \%$ \\
\hline Declined & $0.0 \%$ & $4.3 \%$ & $26.60 \%$ & $18.7 \%$ & $0.70 \%$ \\
\hline Extremely Declined & $0.7 \%$ & $1.4 \%$ & $4.3 \%$ & $5.0 \%$ & $1.4 \%$ \\
\hline
\end{tabular}

Table 10: Chi-Square Analysis with Level of Learning

\begin{tabular}{|l|c|c|}
\hline \multicolumn{2}{|c|}{} & \\
\hline Worse Performance & 57.21 & 0.00 \\
\hline Delivery Impact & 28.322 & 0.00 \\
\hline Final Grade Impact & 61.253 & 0.00 \\
\hline
\end{tabular}

\section{Discussion}

The first research question focused on how the COVID-19 pandemic has impacted student learning in the 2020 - 2021 academic year. It was clear from the student responses that there was at least a minimal impact to the delivery method for their courses. Of the students, $90.4 \%$ reported that the pandemic has required them to go fully remote which lead to a change in their expected course delivery of face-to-face or hybrid classes. Students who were already enrolled in online courses did not assess the same impact as their courses were already designed for remote delivery and the course expectations / instructional content delivery were aligned for this model. While only $32.4 \%$ of the students reported their overall performance 


\section{Issues in Information Systems}

Volume 22, Issue 4, pp. 221-230, 2021

declined in this new environment, it was clear that the acquisition of technology and tools to adapt to this environment proved to be an undue burden on $76.3 \%$ of the respondents.

Additionally, over half of the students reported that the modified instructional delivery due to COVID-19 did have an impact on their grade. We often hear students state that "I learn better when I am in the classroom." Most notably of these metrics is that 20.9 percent of the students felt there was an improvement in their final grade due to change in course delivery while $28.8 \%$ felt their grades were negatively impacted. Over half, $50.4 \%$, felt their grade was unchanged. While the impact on grades alone did not seem as profound, we can't ignore that student learning was also impacted leading a portion of students to report poorer performance and a decrease in overall learning. Lastly, we must consider the students' impact due to the undue burden of acquiring the necessary equipment to conform to the new learning environment and in many students' cases, this posted a financial burden as well.

The second research question focused on how adequately students were prepared for the remote learning that took place during the COVID-19 pandemic. The factors assessed in answering this question involved training received by the students, how well they perceived their instructors were trained for the course delivery, access to needed technology, and any financial considerations for the changes. Only $33.8 \%$ of the students reported they received training for the new tools they were required to use. For students who are new to college or have never taken online / remote courses, this can be a substantial challenge and negatively impact their learning. Students are now being pushed into a self-taught structure for the course content and required to independently access and interact with that content. Training is an area that the university should focus on and if it were available, then a process for awareness and education for the students is imperative. Secondly, only $54 \%$ of the students reported that their instructors seemed adequately trained for the course. While this number may seem low, it is important to realize that a portion of faculty are traditionally teaching using a brick and mortar classroom and this change also posed a major challenge for them to teach the course content in an impactful way. Depending on your ability to adopt new technology quickly, this will impact the degree of course content that can be shared with the students.

Over $80 \%$ of students stated they needed access to a computer, webcam, microphone, and internet during the online delivery. While it may seem that these items are well adopted and already available, we fail to realize how many students are reliant on campus computer labs and internet in lieu of not having the equipment at their fingertips. When these students returned home, they inevitably needed to correct this deficiency which caused varying degrees of burden to them including financial. In some cases, it is possible students did not have access to the internet, even if they had acquired a computer. However, $29.5 \%$ of the students reported that the university provided them technology to complete their work. This number does seem quite low, but it is important to note that students may have already had accommodations, albeit older technology, available to them at home. Of the students who reported that they did not receive technology from the university, $47.4 \%$ stated they had to acquire some equipment to continue their education. Students had relied on their jobs, parents, relief funds, and scholarships as sources to help offset this added cost. When reviewing these numbers, we do believe students were able to acquire, through some means, the necessary technology and tools to get their work done. But more importantly, the process to attain these, the lack of university resources, and potentially limiting circumstances at home did not adequately prepare students for this changing environment. At a minimum, they faced a period of time where they had to acquire what was needed, self-learn new technology, and conform to a new learning environment.

\section{Conclusion}

It is important to note that we should be careful in delineating the difference in assessing distance education and the use of Information and Communication Technology (ICT) in emergency remote learning during 


\section{Issues in Information Systems}

Volume 22, Issue 4, pp. 221-230, 2021

the pandemic. However, an exploration study that highlights students' attitudes, beliefs and their practices during the pandemic may better inform the possible relationships between external and internal variables, and how these relationships differ according to the variables involved in ICT integration in distance education. Examining these relationships could not only help faculty, students and administrators understand the challenges of ICT use better, it could also assist them in uncovering other solutions to overcome the existing barriers and contextual factors based on the relationships among different variables. It is clear from the findings that the swift change to a remote / online environment impacted the students learning and assessments within the course. While this contingency planning is rare, it is important to recognize that access to equipment and proper tools along with adequate training can indeed tip the scales to improve student learning in these emergency situations.

\section{References}

Baczek M, Zaganczyk-Ba ،czek M, Szpringer M, Jaroszynski A, Wozakowska-Kapłon B. Students’ perception of online learning during the COVID-19 pandemic: a survey study of Polish medical students. Medicine 2021;100:7(e24821)

Bernard RM, Abrami PC, Borokhovski E, Wade CA, Tamim RM, Surkes MA, et al. A meta-analysis of three types of interaction treatments in distance education. Rev Educ Res. 2009;79(3):1243-1289. doi: $10.3102 / 0034654309333844$

Docherty A, Sandhu H. Student-perceived barriers and facilitators to elearning in continuing professional development in primary care. Educ Prim Care 2006;17:343-53

Donkin R, Askew E, Stevenson H. Video feedback and e-Learning enhances laboratory skills and engagement in medical laboratory science students. BMC Med Educ. 2019;19:310. https://doi.org/10.1186/s12909-019-1745-1

Elfirdoussi, S., Lachgar, M., Kabaili, H., Rochdi, A., Goujdami, D., \& Firdoussi, E. (2020). Assessing distance learning in higher education during the COVID-19 pandemic. Education Research International, Vol 2020, Article ID 8890633

Man Kit Ho, I., Cheong, K., \& Weldon, A. (2021). Predicting student satisfaction of emergency remote learning in higher education during COVID-19 using machine learning techniques. PLosONE 16(4): e0249423 https://doi.org/10.1371/journal.pone.0249423

Keis O, Grab C, Schneider A, Ochsner W. Online or face-to-face instruction? A qualitative study on the electrocardiogram course at the University of Ulm to examine why students choose a particular format. BMC Med Educ. 2017;17(1):194. doi: 10.1186/s12909-017-1053-6

Mukhtar K, Javed K, Arooj M, Sethi A. Advantages, Limitations and Recommendations for online learning during COVID-19 pandemic era. 2020;36(COVID19-S4):COVID19-S27-S31. doi: https://doi.org/10.12669/pjms.36.COVID19-S4.2785

Murgatrotd, S. (2020, March). COVID-19 and online learning. Alberta, Canada. Doi:10.13140/RG/2/2/31132.85120 


\section{Issues in Information Systems}

Volume 22, Issue 4, pp. 221-230, 2021

Niebuhr, V., Niebuhr, B., Trumble, J, et.al. (2014). Online faculty development for creating e-learning materials. Edu Health 2014;27-255-61

Pokhrel, S., \& Chhetri, R. (2021). A literature review on impact of COVID-19 pandemic on teaching and Learning. Higher Education for the Future, 8 (1) 133-141, 2021

Schleicher, A. (2020). The impact of COVID-19 on education. Insights from education at a glance 2020. Education at a Glance. https://www.oecd.org/education/the-impact-of-covid-19-on-educationinsights-education-at-a-glance-2020.pdf

Soltanimehr E, Bahrampour E, Imani MM, et al. Effect of virtual versus traditional education on theoretical knowledge and reporting skills of dental students in radiographic interpretation of bony lesions of the jaw. BMC Med Educ. 2019;19:233. https://doi.org/10.1186/s12909-0191649-0. 6

United Nations. (2020). Policy Brief: Education during COVID-19 and beyond. United Nations. https://www.un.org/development/desa/dspd/wpcontent/uploads/sites/22/2020/08?sg_policy_brief_covid-19_and_education_august_2020.pdf

Varthis S, Anderson OR. Students' perceptions of a blended learning experience in dental education. Eur J Dent Educ. 2016:1-7. https://doi.org/ 10.1111/eje.12253 